\title{
A Study on Accounting Management System
}

\author{
Dongmei Jing \\ Xijing University, Xi' an Shaanxi, 710123, China
}

Key words: Accounting, Management system, Research.

\begin{abstract}
Accounting management system is an important part of the state economy management. A rational accounting management system cannot only bring about high development benefit, but also promote enterprises' implementation, guaranteeing the accuracy and authenticity of accounting information, and meeting the needs of socialist market economy and the need of self-development of enterprises. Moreover, different social and economic environments require different accounting management systems. Therefore, to adapt the accounting management system to the needs of modern development, we should innovate the accounting management system, so as to realize new market system. This paper will cover various aspects of accounting management system, as below.
\end{abstract}

\section{Introduction}

Since China's economy is developing rapidly, a rational accounting management system is helpful for maintaining the market order to give full play to it. With the constant reform of the economic system, the government authority has performed in-depth research on some systems, having gathered various opinions. Besides, the innovativeness also conforms to the development requirements of the modern socialist market economy system.

\section{Problems of China's Accounting Management System}

Under the current development tendency, China is in the socialism period and the level of market economy rises rapidly. But actually, related systems that are the basic conditions of China's national economy are still obsolescent and unvital. There are severe government-enterprise problems, and it is difficult to differentiate the property right either. This largely restricts the development of China's economic system reform. Moreover, under this system, enterprises don't hold the dominant position, and positive management over enterprises has not been performed, leading to a series of problems in enterprise operation. People are getting to realize the importance of accounting system. Especially under the new reform system, traditional accounting system cannot meet the requirements of modern development. The main problems are as follows.

\section{Information Distortion}

Some accounting entities in China are not enough independent, so that they are not honest in handling financial receipts and disbursements, and cause state-owned capital loss. What's worse, this has become a universal phenomenon in China. Under the current development tendency, the accounting information provided by many enterprises is distorted, which doesn't only affect China's economic development order and weaken the optimized implementation of the capital market, but also reduce the reform requirements of the economic system.

\section{Slack Supervision}

Under the current system, the supervision system of China's accounting management system still has some problems. Although laws and regulations on accounting have been promulgated, the laws and 
regulations are not truly implemented, so that accounting personnel just symbolically follow the laws and regulations. Moreover, the business status of accounting personnel and the legal status of accounting supervision are not recognized. Instead, accounting personnel are regarded as the private property of the legal representative, so that the independence of accounting cannot be guaranteed. In real work, the accounting personnel in some government sectors, under the corporate governance structure, are regarded as employers of companies. Not only that they cannot execute their supervision power, but also their function and power are nominal.

\section{Incomplete System}

Under the current accounting laws and regulations system, there are some problems. No established laws and regulations are available for identifying some false information. Besides, it is impossible to define the legal responsibilities for accounting. In juridical practice, some false information cannot be disclosed, and the links of releasing original certificates and statements also have problems, such as financial staff, supervision organization and accounting information, and so on. The legal responsibilities for the abovementioned links have not been clearly defined yet.

\section{Unprofessional Staff}

Most accounting personnel are not professional enough. This is mainly because some accounting personnel haven't grasped national policies, laws, regulations and related systems, and don't have professional ethics as required. Thus, in actual accounting activities, they often violate national policies, laws or regulations, and are incapable of correctly handling and calculating related accounting events and financial affairs. Furthermore, in real work, they have no sense of responsibility and principle, which results in that the quality of accounting information cannot be guaranteed.

\section{Improvement of China's Accounting Management System}

China is a socialist country, and implements macro-control and market economy simultaneously for economic management. Under the new economic development environment, China's economic management mode has been constantly improved. Thus, it needs to combine China's macro-control idea with market economy and legislation, and establish a management mode conforming to the development of modern society and suitable for corporate management mode, which is not only good for giving full play to the competitive advantages of China's market economy, but also promoting the development of its independence. Generally, China's accounting management system, through intensified reform, is mainly reflected in the following aspects [1].

\section{Accountant Designation System}

Accounting is an independent division of enterprise, professional staff of an enterprise and a country, uniformly executed by related functional department of the state, and formed via assessment, reward, and so on. Accounting personnel of state-owned enterprise are designated by the state, mainly perform accounting calculation and accounting supervision, and are main representatives of national interests. With the constant development and construction in recent years, the accountant designation system is widely implemented. Under such a system, the supervision and management can be guaranteed, and the legitimate rights and interests of accounting personnel also can be maintained, and their problems can be effectively solved. Therefore, attention should be paid to related problems in the process of implementing the system. The accountant designation system is different from the economic system reform thought, so attention also should be paid to the system structure. Furthermore, it will take a high cost to supervise the designated accounting personnel, which is not good for the formation of benefit. 


\section{Chief Financial Officer System}

The chief financial officer system is an accounting management system in which large and medium-sized enterprises directly designate chief financial officer to safeguard the control position of the state in state-owned enterprises. The chief financial officer system has some advantages, which can grasp the law of accounting activity in the economic transition period. The supervision and management over chief financial officer designated by the government are for the sake of property right, which constrains the supervision relations. In addition, the chief financial officer system also relates to the functions of financial management and supervision of accounting personnel and internal auditor, which cannot only make up the shortcomings the function and power of enterprise organization, but also prevent the financial staff from being dishonest in receipts and disbursements. Meanwhile, through innovation, this system doesn't only conform to the simplification principle of the government, but also can meet the formation of the cost-effective principle.

\section{Treasury Centralization Payment System}

Government's financial funds are kept in the national treasury, and all fiscal expenditures of budget units are really incurred and distributed by the national finance. Under the treasury centralization payment system, the fund-spending units perform whole-process supervision from budget, distribution, fund appropriation, and fund use. The establishment of this system has eliminated a series of problems, such as multiple accounts, multi-link fund appropriation, fund precipitation, non-transparency of fund implementation, and low profit from fund use [2].

\section{Measures for Improvement of Accounting Management System}

\section{Improvement of Legal System of Accounting}

The legal system of accounting is a systematic implementation project. To improve it, the Accounting Law should be analyzed first, and taken as the guidance to promote the completeness of the enforcement of laws and regulations. Besides, the false accounting information also should be identified, and proper laws and regulations should be established. The links of false accounting information should be clearly identified, to promote the full implementation of responsibilities, and guarantee the truth of supervision, audit and responsibility. Besides, measures should be taken to ensure strict punishment, compensation and implementation, so as to ensure the operability of the Accounting Law. In addition, measures should be taken to promote the formation of the accounting legal supervision system, and strictly supervise the fulfillment of accounting personnel of legal responsibilities. Meanwhile, with the development of modern science and technology, the information technology should be made full use of to realize information and digitalization development of analysis, change the traditional management theory and mode, and guarantee the reasonable formation of new accounting model.

\section{Construction of Internal and External Supervision System}

As to the construction of internal and external supervision system, three requirements should be met. Firstly, to realize the chief financial officer designation system, the chief financial officer designation system has been widely established, and good development effect has been achieved. The formation of this system has not only changed the situation where accounting personnel are restricted by related factors, but also provides good implementation strategy to chief financial officer, to promote optimized implementation of operation and management, and guarantee the realization of financial activities in daily supervision and management. Secondly, an internal accounting control system should be established for enterprise. Under this system, it can be realized that all personnel can be isolated and restrict each other. For some important economic events, this system also has the functions of supervision and restriction in decision-making and implementing process, can enhance the rationality and accuracy of financial check range, realize strict check deadline and organizational procedures, and promote regular implementation of internal audit work. Thirdly, measures should be 
taken to give full play to social audit and supervision and government's supervision function. Presently, most accountants haven't fulfilled their supervision function. Hence, in view of this situation, measures should be taken to enhance the effectiveness of audit work of accounting personnel, and ensure effective promotion of the intensity of supervision [3].

\section{Adjustment of Administrative Function}

The accounting administration function of government agency should be actively adjusted, to ensure that the accounting management responsibilities of government sectors are clearer. To meet the current needs of the market economy system, the government's administrative functions should be changed, a system meeting the requirements of modern enterprises should be established, and the government's accounting administration function should be properly adjusted, to ensure that the responsibilities of accounting personnel of each government sector can be fully fulfilled and the accounting personnel can fully play their role with the scope of official duty.

\section{Establishment of Self-regulation Mechanism}

The establishment of the self-regulation mechanism gives authority to accounting personnel management according to their autorhythmicity and sense of organization, to ensure the establishment of a uniform and normative code of professional ethics, and promote the normativity of accounting activities. To form the self-regulation mechanism, the organizational affiliation of the designated personnel and key personnel of accounting calculation should be clearly defined, a complete assessment system should be established for accounting personnel, and accounting personnel should be examined for the qualification of post. In addition, efforts should be made in strengthening professional ethics construction of accounting personnel, and education and training should be offered, so as to improve the comprehensive abilities of accounting personnel as far as possible.

\section{Establishment of Credit Appraisal System}

In recent years, pilot projects of credit appraisal system of financial accounting have been carried out in Shanghai and other regions, which have greatly promoted the formation of the credit appraisal system. For example, accounting enquiry system and follow-up management system require basic accounting work and accounting information quality as the main basis for appraisal and assessment. This mode cannot only raise accounting personnel's consciousness of responsibility, and financial staff's comprehensive abilities and consciousness, but also promote the completeness of the internal management system, and ensure a good credit atmosphere is formed internally, so as to provide construction opinions [4].

Based on the above analysis and discussion, to establish an accounting management system in line with the development of socialist market economy and with its own characteristics, the government functions, civil functions and the role of groups should be played. According to the actual development situation, measures should be taken to promote the effective formation of accounting regulations, and ensure strict supervision and examination under the positive guidance of the government and the coordination of information service and organization optimization, so as to largely raise the level of accounting activities.

\section{Development Tendency of Accounting Management System}

Large progress and development of the accounting management system have achieved, and new forms have been realized [5]. Firstly, accountancy emerged and formed with the development of economy, and different accounting systems are needed in different countries that are in different development stages. As far as China is concerned, China is at the initial development stage of socialism, and its productivity and level of production vary from region to region. To meet the needs of the modern socialism market and promote social development, the accounting system must be reformed, so as to promote the formation of economic foundation and further improve the 
productivity. Secondly, presently, China is undergoing constant reforms. Such a circumstance also provides a chance for the innovation of the accounting system, and promoting the formation of reform in the new period. With the development of market economy, various contradictions exist. Thus, to reduce the risks and promote the steady increase of productivity effect, we must implement modern management systems. Under the accounting management system, fair and impartial analysis of rights, interests, and responsibilities of enterprises, and rational assessment on the proxy responsibility and performance of enterprises can be realized, to promote the formation of harmonious and steady relations. Thirdly, an independent professional accounting market can be formed in a real sense. In such market, market economy is taken as the basic conditions for its development, so as to prevent it from depending on other organizations, and ensure that both macro-benefit and micro-benefit of the accounting system are given full play in market economy. Under such tendency, not only the standard operation of China's socialist market economy can be guaranteed, but also its efficient development can be promoted.

\section{Summary}

China is being in the critical period of economic development and construction, when the accounting management system plays an important role. A good accounting management system can not only promote the good development of enterprises and ensure the steady increase of economic profit, but also maintain the socialism market order. In view of the current market development situation of China, innovative development of accounting management system should be realized to promote the sustainable economic construction.

\section{References}

[1] Yu Guomin. A Study on Establishment of Public Accounting Management System from the Perspective of Public Finance, Accounting Learning,2016(7):126.

[2] Lu Jianying. Comparison between Chinese and Thai Accounting Management Systems*--Thought Based on the Background of China-ASEAN Accounting Area Coordination, Friends of Accounting,2014(36):94-96.

[3] Zeng Junjie. Exploration of China's Accounting Management System Reform in the New Period, Industrial \& Science Tribune, 2015,14(15):226-227.

[4] Li Huili. A Study on Idea and Method of Accounting Management System Reform of Public Institutions in the New Period, China Collective Economy, 2014(25):117-118.

[5] Su Yanshuang. On Accounting Information Management in Accounting Management System Reform, New Technology \& New Products of China, 2012(16):215-215. 